second (PD20) might reflect partially distinct pathophysiological phenomena [1].

In our study, we did not find a relationship between bronchial hyperresponsiveness (PD20) and the change from baseline of the cough score. This applied to smokers as well as nonsmokers (both $\mathrm{p}>0.80$ ) [2].

The "increasing evidence" regarding the mechanism of eosinophilic bronchitis refers to small uncontrolled studies $[3,4]$ or studies in severely obstructive patients $[5,6]$. In the study by PIZZICHINE et al. [7], 44 adults (32 nonsmokers), with a daily bothersome cough for $\geqslant 1 \mathrm{yr}$, were included. None of the patients had sputum eosinophilia, and no effect was found of a 2-week treatment with budesonide compared with placebo.

Eosinophilic bronchitis occurs in $10-30 \%$ of patients referred to a specialist for chronic cough [8-10], and in 14 out of $82(17 \%)$ primary care patients with cough (mean (range) duration 11 months (1-96)) [11]. However, in a subset of 36 patients who responded to budesonide only, seven out of 34 (thus, not more than in the studies mentioned previously) fulfilled the criterion for sputum eosinophilia (>3\%) [12].

Interestingly, in our study [2], as well as the study of RYTILA et al. [12], cough appears to be at least as sensitive to antiinflammatory therapy compared with other lower respiratory tract infection symptoms like wheeze and dyspnoea. Nevertheless, we agree with F. Hargreave and K. Parameswaran that the measurement of airway inflammation may help to clarify the mechanism of action of anti-inflammatory medications.

Cough may be a target symptom in studies of the mechanisms of anti-inflammatory treatment for lower respiratory tract symptoms in healthy subjects. The recent literature and the results of our study [2] suggest that investigation of sputum in nonsmoking patients, who present with unexplained cough to their doctor, is feasible and worthwhile.

B.P. Ponsioen*, P.N.R. Dekhuijzen" , A.M. Bohnen* and N.A. Vermue

*Dept of General Practice, Erasmus Medical Centre, Rotterdam, "University Medical Centre, Nijmegen, and "GlaxoSmithKline, Zeist, The Netherlands.

\section{REFERENCES}

1 van Rensen ELJ, Straathof KCM, Veselic-Charvat MA, Zwinderman AH, Bel EH, Sterk PJ. Effect on inhaled steroids on airway hyperresponsiveness, sputum eosinophils, and exhaled nitric oxide levels in patients with asthma. Thorax 1999; 54: 403-408.

2 Ponsioen BP, Hop WC, Vermue NA, Dekhuijzen PN, Bohnen AM. Efficacy of fluticasone on cough: a randomised controlled trial. Eur Respir J 2005; 25: 147-152.

3 Gibson PG, Dolovich J, Denburg J, Ramsdale EH, Hargreave FE. Chronic cough: eosinophilic bronchitis without asthma. Lancet 1989; 1: 1346-1348.

4 Pavord ID, Brightling CE, Woltmann G, Wardlaw AJ. Noneosinophilic corticosteroid unresponsive asthma. Lancet 1999; 353: 2213-2214.

5 Pizzichini E, Pizzichini MM, Gibson P, et al. Sputum eosinophilia predicts benefit from prednisone in smokers with chronic obstructive bronchitis. Am J Respir Crit Care Med 1998; 158: 1511-1517.

6 Brightling CE, Monteiro W, Ward R, et al. Sputum eosinophilia and short-term response to prednisolone in chronic obstructive pulmonary disease: a randomized controlled trial. Lancet 2000; 365: 1480-1485.

7 Pizzichini MMM, Pizzichini E, Parameswaran K, et al. Non-asthmatic chronic cough: no effect of treatment with an inhaled corticosteroid in patients without sputum eosinophilia. Can Respir J 1999; 6: 323-330.

8 Brightling CE, Ward R, Goh KL, Wardlaw AJ, Pavord ID. Eosinophilic bronchitis is an important cause of cough. Am J Respir Crit Care Med 1999; 160: 406-410.

9 Carney IK, Gibson PG, Murree-Allen K, Saltos N, Olson LG, Hensley MJ. A systematic evaluation of mechanisms in chronic cough. Am J Respir Crit Care Med 1997; 156: 211-216.

10 Ayik SO, Basoglu OK, Erdinc M, et al. Eosinophilic bronchitis as a cause of chronic cough. Respir Med 2003; 97: 695-701.

11 Rytila P, Metso T, Petays T. Eosinophilic airway inflammation as an underlying mechanism of undiagnosed prolonged cough in primary healthcare patients. Respir Med 2002; 96: 52-58.

12 Rytila P, Metso T, Heikkinen K, Saarelainen P, Helenius IJ, Haahtela T. Airway inflammation in patients with symptoms suggesting asthma but with normal lung function. Eur Respir J 2000; 16: 824-830.

\title{
EUS: confusion about terminology and its consequences
}

\section{To the Editors:}

In the March 2005 issue of the European Respiratory Journal, three original articles by ANNEMA et al. [1], CADDY et al. [2], and RINTOUL et al. [3], accompanied by an editorial by VILMANN and LARSEN [4], appeared on ultrasound (US)-guided endoscopic needle aspiration of mediastinal lymph nodes. All of these articles unquestionably contribute to the growing body of evidence that sampling of lymph nodes or masses in the chest using an endoscopic tool has a high yield and is safe. This letter was prompted by the new meaning of the abbreviation "EUS". The term endoscopy in the chest comprises the four entities: 
bronchoscopy, oesophagoscopy, mediastinoscopy and thoracoscopy. When talking about endoscopy only, the access to the chest is not defined. Likewise, an US-guided procedure is linguistically coupled with the route used, such as the transthoracic (TT), endobronchial (EB), or oesophageal (E) route. When performing a bronchoscopy, the correct term is EBUS, when oesophagoscopy is used it is EUS. Earlier articles on EUS used the letter " $E$ " correctly for "oesophageal" or even better "transoesophageal" [5], but, more recently, it has been used for "endoscopic" [1-3, 6], which is incorrect. Sadly, even leading journals have started to accept this change. It is thus not surprising that in the article by RINTOUL et al. [3], the title had to start with a misnomer: "Endobronchial and endoscopic ultrasound-guided real-time fine-needle aspiration for mediastinal staging". Is endobronchial not endoscopic?

Unfortunately, the problem is not only a semantic one. Highjacking the " $\mathrm{E}$ " in EUS for "endoscopic" implies that "oesophageal" can be equated with "endoscopic", insinuating that the other endoscopic techniques are inferior. In the article by ANNEMA et al. [1], which uses oesophageal US-guided sampling of mediastinal nodes for the diagnosis of sarcoidosis, it is stated in the conclusion that endoscopic (they mean oesophageal) US-guided (=EUS) fine-needle aspiration (FNA) should be the next step after a negative bronchoscopy. This conclusion was based on the fact that EUS had an impressive yield of $82 \%$ in sarcoidosis patients after a negative bronchoscopy. In their series of 51 patients, however, only 36 had undergone bronchoscopy, and, surprisingly, the reader is not told what was done at bronchoscopy! Bronchoscopy using EBUS-transbronchial needle aspiration (TBNA) might have resulted in the same yield as was obtained by EUS-FNA. To maintain their conclusion, the authors should have compared EUS-FNA prospectively with EBUS-TBNA.

The most important issue in the evolving role of various sampling techniques, however, is to differentiate between situations when the available endoscopic procedures are complementary and when they are competitive. A subcarinal lymph node will be successfully sampled by any endoscopic method; thus, they all compete. Paraoesophageal lymph node stations eight and nine are the undisputed domains of EUSFNA, just as anterior tracheal or right hilar nodes are the domains of EBUS-TBNA. The choice of the tool to be used lies in the accessibility of the tissue to be sampled, and, among competitive methods, the least invasive one should be chosen. When sampling for benign disease, any tissue delivering the diagnosis is sufficient. In bronchogenic carcinoma, however, diagnosis and endoscopic staging can often be combined [7]. In this situation, bronchoscopy should be the first procedure of choice as it can sample peripheral lesions, screen for synchronous endoscopically visible cancer, and stage all lymph nodes adjacent to the tracheobronchial tree as well.

The evolving consensus, corroborated by the current three studies [1-3], is that the role of both EBUS-TBNA and EUSFNA will increase, whereas mediastinoscopy will substantially decrease, at least in centres that have the skills and the financial resources to offer EBUS-TBNA and EUS-FNA.

In order to discuss the relative merits of the "new kids on the block", i.e. endobronchial ultrasound-guided transbronchial needle aspiration and oesophageal ultrasound-guided fineneedle aspiration, let's start by getting the terminology right.

\section{C.T. Bolliger}

Dept of Internal Medicine, Tygerberg Hospital, Cape Town, South Africa.

\section{REFERENCES}

1 Annema JT, Veselic M, Rabe KF. Endoscopic ultrasoundguided fine-needle aspiration for the diagnosis of sarcoidosis. Eur Respir J 2005; 25: 405-409.

2 Caddy G, Conron M, Wright G, Desmond P, Hart D, Chen RY. The accuracy of EUS-FNA in assessing mediastinal lymphadenopathy and staging patients with NSCLC. Eur Respir J 2005; 25: 410-415.

3 Rintoul RC, Skwarski KM, Murchison JT, Wallace WA, Walker WS, Penman ID. Endobronchial and endoscopic ultrasound-guided real-time fine-needle aspiration for mediastinal staging. Eur Respir J 2005; 25: 416-421.

4 Vilmann P, Larsen SS. Endoscopic ultrasound-guided biopsy in the chest: little to lose, much to gain. Eur Respir J 2005; 25: 400-401.

5 Fritscher-Ravens A, Soehendra N, Schirrow L, et al. Role of transesophageal endosonography-guided fine-needle aspiration in the diagnosis of lung cancer. Chest 2000; 117: 339-345.

6 Fritscher-Ravens A, Davidson BL, Hauber HP, et al. Endoscopic ultrasound, positron emission tomography, and computerized tomography for lung cancer. Am J Respir Crit Care Med 2003; 168: 1293-1297.

7 Diacon AH, Schuurmans MM, Theron J, et al. Utility of rapid on-site evaluation of transbronchial needle aspirates. Respiration 2005; 72: 182-188.

DOI: $10.1183 / 09031936.05 .00036705$

From the authors:

We have read with interest the comments by C.T. Bolliger on the terminology regarding ultrasound-guided biopsies of mediastinal lymph nodes. Obviously, and here we fully agree, there should be a consensus on the nomenclature of a new diagnostic method. The development of echo-endoscopes, which make accurate imaging and real-time controlled biopsies of lesions along the gastro-intestinal tract possible, is regarded as one of the greatest improvements in endoscopy of the last 20 yrs [1]. The name given to this technique was endoscopic ultrasonography or endoscopic ultrasound and was abbreviated as EUS. Depending on the organ under investigation (oesophagus, stomach or rectum), authors have

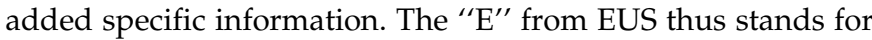
"endosonography" or "endoscopic" and not for "oesophagus", as suggested by C.T. Bolliger. According to his suggestion, how should the well-established term "rectal EUS" be translated? Reviewing the literature specifically on ultrasound (US)-guided biopsies of mediastinal lymph nodes from the oesophagus (using Pubmed), various authors, so far, 